\title{
Study on the Mechanism of Nugget Growth Behavior in Three Sheets Stack Resistance Spot Welding
}

\author{
Nazmul Huda*, Dae-Geun Nam** and Yeong-Do Park***, ${ }^{*}$ \\ * Department of Mechanical and Mechatronics Engineering, University of Waterloo, Waterloo, \\ Ontario, N2L 3G1, Canada \\ **Dongnam Regional Division, Korea Institute of Industrial Technology, Busan, 46742, Korea \\ ***Department of Advanced Materials Engineering, Dong-Eui University, Busan, 47340, Korea
}

†Corresponding author : ypark@deu.ac.kr

(Received December 1, 2019 ; Revised December 5, 2019 ; Accepted December 16, 2019)

\begin{abstract}
The present study focused on finding a mechanism to achieve good weldability in three sheets spot welding. Two combinations of three sheets (Al-HPF combinations with mild steel / HPF steel / DP steel stacking) and (TRIP combination with mild steel / TRIP780 steel / DP590 steel stacking) were used. Weld quality was evaluated by measuring the button diameter after peel test, and peak load measurement using a tensile shear test. A high speed camera and simulation (SORPAS) were used to investigate the nugget growth mechanism. The Al-HPF combinations showed higher nugget growth rate in the sheet thickness direction, however the TRIP combination showed higher nugget growth rate in the sheet rolling direction. Also, the TRIP combination produced a larger nugget diameter (or higher penetration) in the thin sheet of interface "A" than the Al-HPF combination. The main reason for the larger nugget diameter in the TRIP combination was the higher current density and wider current path resulting from the high indentation on interface "A". The selection of a middle sheet with optimum electro-mechanical properties for the three sheet stack can improve the weldability of three sheets spot welding for car body construction.
\end{abstract}

Key Words : Resistance spot welding, Three sheets stack spot welding, Tensile shear strength, Nugget growth, Current density, Nugget diameter

\section{Introduction}

Three sheets spot welding is more complicated compared to two sheets spot welding as nugget needs to be formed in all three sheets. Different types of similar and dissimilar combination of three sheets spot welding are currently applied in some complex structure of automobile body such as front longitudinal rails, A, B, C- pillars and the bulk head to inner ring ${ }^{1)}$. The complication involved in three sheets spot welding is nugget growth in a thin sheet. If one of the external sheet is thinner than the other two sheets, the interface between thin and the middle sheet is located closer to the electrode. High cooling occurs by electrode water circulation in this interface compared to thick-thick interface. If the heat in- put is low, this might not be sufficient for nugget formation in thin-thicker sheet interface. At high heat input, nugget may form in thin-thick sheet interface but might cause expulsion in thick-thick sheet interface. The introduction of the coating layer, surface quality, and alignment make three sheets spot welding more complicated. Methods, like the use of different size electrodes in two sides of sheets, use of process tape of proper resistance ${ }^{2)}$, forging force ${ }^{3)}$ and use of shunting method $^{4)}$ have been studied by several authors. All the methods mentioned above, the purpose is to make heat balance between two interfaces of sheets and thereby helping nugget formation in the thinner sheet and also reduce the probability of expulsion in thick-thick sheet interface. However, these methods are not easily applicable currently in all industries. Therefore, researchers 
have to rely on varying the weld time, weld current, electrode force, pulsing system and material combinations. The present study focused on finding a mechanism to achieve improved weld quality (or larger nugget diameter) in three sheets spot welding by observing and comparing the heat generation and nugget growth of two different combinations of three sheets stacking.

\section{Materials}

In this study, two combinations [(GA SGARC $(0.7 \mathrm{t})+$ Al-HPF (1.2t) + DP $590(1.4 \mathrm{t}))$ and (GA SGARC (0.7t) + TRIP $780(1.2 \mathrm{t})+$ DP $590(1.4 \mathrm{t}))$ ] of three sheets of total thickness $3.30 \mathrm{~mm}$ was used for welding with keeping top and bottom sheet constant. In the following sections, the two combinations will abbreviated as AlHPF combination and TRIP combination respectively, where the top sheet is GA SGARC and the bottom sheet is DP590. The GA SGARC having galvannealed coating layer of thickness $11 \mu \mathrm{m}$. In the Al-HPF combinations, the middle sheet was Al-HPF which having Al-Si coating layer of $32 \mu \mathrm{m}$ thickness. The chemical composition of Al-HPF contains $0.23 \%$ carbon, $0.26 \%$ silicon, $1.24 \% \mathrm{Mn}$, etc. However, for TRIP combinations, the middle sheet was cold-rolled TRIP 780.Its chemical com- position consists of $0.099 \%$ carbon, $1.35 \%$ silicon, $2.35 \% \mathrm{Mn}$, etc. The bottom sheet DP 590 was also cold rolled.

\section{Welding Equipment and Procedure}

Pedestal type AC welding controller was used to perform the multiple sheets welding. The sheets dimension was $100 \mathrm{~mm} \times 30 \mathrm{~mm}$ (length $\mathrm{x}$ width) and welding was performed according to the setup shown in Fig. 1. Electrode force of $3.5 \mathrm{kN}$, squeeze time 70 cycle, Single pulse of 21 cycles weld time and 15 cycles of hold time were set during welding. Dome radius type $\mathrm{Cu}-\mathrm{Cr}$ electrode of $6.0 \mathrm{~mm}$ diameter was used for welding. Tensile shear tests (TST) were carried out in a universal tensile test machine of load capacity $100 \mathrm{kN}$

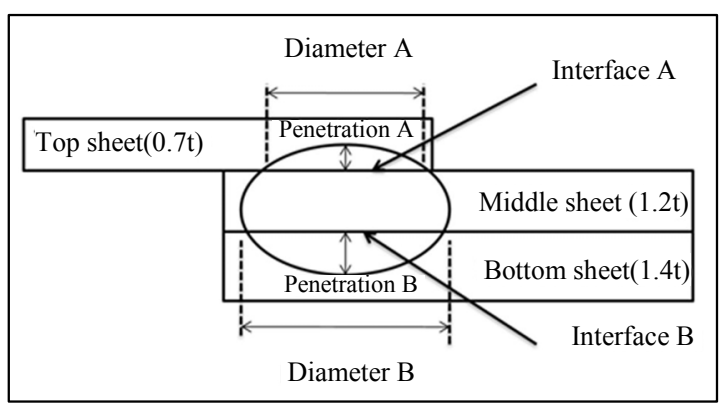

Fig. 1 Schematic of three sheets stack resistance spot welded tensile test specimen by pulling a thin sheet apart from two high strength steels. The acceptable weld current range was determined based on attaining a minimum button diameter of 3.30 $\mathrm{mm}$ in interface A (thin-thick sheet interface) after the tensile test. The dynamic resistance and expulsion criteria were monitored by the dynamic resistance measuring system. Expulsion conditions were confirmed by observing dynamic resistance during welding. For metallographic analysis, nugget growth and the bonding mechanism was monitored by stereomicroscope and optical microscope Olympus BX51M. The microstructure of the welded parts were revealed by using picral etchant $(1 \% \mathrm{HCl}, 3 \%$ picral and $96 \%$ ethanol). For high speed camera video, the experimental schedule used is $1.75 \mathrm{kN}$ electrode force, welding current $3.0 \mathrm{kA}$ and weld time 21 cycles with half-cut electrode on both sides. All the value is chosen half of the actual welding except the weld time for better imaging of heat generation and melting. The frame rate of high speed camera is set 2000 frame/second with a shutter speed 1/4000 sec.

\section{Results and Discussion}

\subsection{Weld growth curve}

The weld quality of three sheets spots welding can be inspected by button diameter in interface " $A$ " after the tensile test. In the purpose of gaining a good weldability nugget must be formed in thin sheet. The resistance spot welding usually consists of interfacial fracture, partial interfacial fracture and button fracture. Button fracture is defined based on gaining a minimum button diameter of $3.30 \mathrm{~mm}$ in interface " $\mathrm{A}$ " after the tensile test. The welding current is varied from $5.0 \mathrm{kA}$ to 10.5 $\mathrm{kA}$ with $0.5 \mathrm{kA}$ increment. Based on minimum button diameter in interface "A", Al-HPF combinations having a weldable current range of $3.0 \mathrm{kA}$ while TRIP combinations are having $2.5 \mathrm{kA}$ (Fig. 2). At $6.0 \mathrm{kA} \mathrm{Al-HPF}$

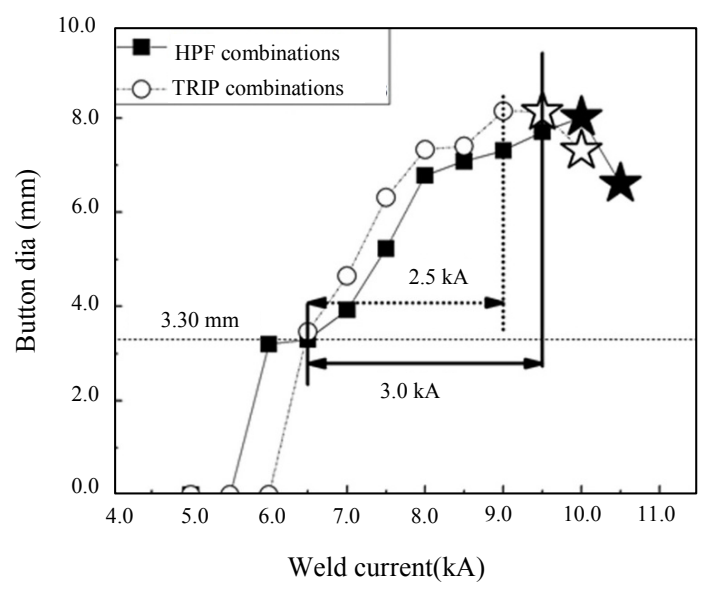

Fig. 2 Button diameter on interface "A" with increasing resistance spot welding current for hot press forming steel and TRIP steel combinations 
shows a partial interfacial fracture but TRIP combination shows a fully interfacial fracture. Both the Al-HPF and TRIP combination shows a satisfactory button $(3.30 \mathrm{~mm})$ formation initiation at $6.5 \mathrm{kA}$. the TRIP combinations possess a higher button diameter in all welding current after $6.0 \mathrm{kA}$, except the expulsion conditions due to higher heat generation caused by joule heating at the same welding current. At expulsion condition, button diameter cannot be compared as molten metal squeeze out of fusion zone. The TRIP combination shows expulsion (star mark) at $9.5 \mathrm{kA}$ while the HPF combination shows expulsion at $10.0 \mathrm{kA}$.

\subsection{Weld strength curve}

The minimum acceptable peak load value in the tensile test is $2.79 \mathrm{kN}$. According to this, the Al-HPF combination possesses a weldable current range of $1.5 \mathrm{kA}$ and the TRIP combination, also having a weldable current range of $1.5 \mathrm{kA}$ (Fig. 3). For Al-HPF combination the weldable current range of $3.0 \mathrm{kA}$ based on button diameter, is reduced to $1.5 \mathrm{kA}$ based on weld strength. However, for TRIP combination, the weldable current range of $2.5 \mathrm{kA}$ (based on button diameter) is reduced to $1.5 \mathrm{kA}$ (based on weld strength). Al-HPF combination weldable current range is reduced by $1.5 \mathrm{kA}$, but the TRIP combination shows a reduction of $1.0 \mathrm{kA}$ based on weld strength. The Higher reduction in weldable current range base on weld strength in Al-HPF combination is due to the lower button diameter in interface "A". Usually, lower button diameter provides lower tensile strength. At $6.0 \mathrm{kA}$, the Al-HPF combination shows higher tensile strength than the TRIP combination. Though both having interfacial fracture at 6.0 kA but Al-HPF combination having a partial interfacial fracture of $3.00 \mathrm{~mm}$. However, at this welding

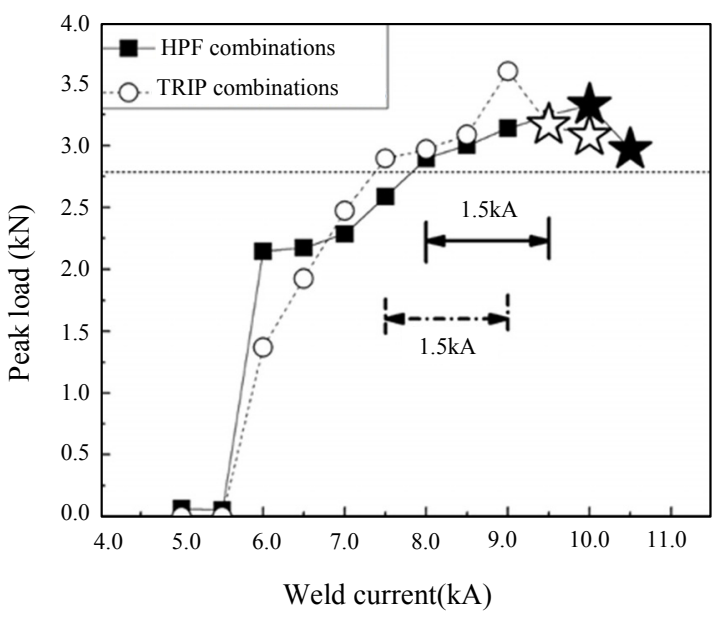

Fig. 3 Tensile shear strength on interface " $A$ " with increasing resistance spot welding current for hot press forming steel and TRIP steel combinations current TRIP combination having a fully interfacial fracture, which results in the high tensile load for Al-HPF combination at $6.0 \mathrm{kA}$. At higher current, the TRIP combinations possess higher button diameter thereby shows higher tensile strength

\subsection{Heat generation and Nugget growth}

To investigate the reasons which phenomena influences TRIP combination higher button diameter in a thin sheet, the heat generation and nugget growth pattern is observed in a particular current $(7.5 \mathrm{kA})$ in five cycles for both combinations. The evaluation shows, heat generation in the interfaces of sheets and also the sheets. Generally, the sheet/sheet interface provides superior resistance of electric current flow, which allows nugget to form in interface rather than in bulk materials. There is significant difference in heat generation in the interface " $A$ " and interface " $B$ ". The interface " $A$ " of Al-HPF and TRIP combination is closer to the electrode, therefore cooling is high in this interface. Moreover, due to electrode force, acute stress localization might occur between electrode to top sheet contact edge and also between top to middle sheet interface. This localized stress might cause the deformation of the top sheet. This high deformation will lead to a change in the contact pressure and contact area in the faying interface. Higher stress in this interface might lead to lower contact resistance, and heat generation will be less in the interface " $\mathrm{A}$ "1). The comparison between two combination heat generation at $7.5 \mathrm{kA}, 1$ cycle in the interfaces shows Al-HPF combination having high heat generation in the interfaces than TRIP combination ${ }^{5}$. The reason might be due to the higher interfacial contact resistance due to the Al-HPF coating layer and contamination of surfaces ${ }^{4}$. Carbon (like greases) is the main cause of contamination, which can be burned during welding. Moreover, as the Al-Si coating layer having high hardness, therefore, contact area is not uniform in the interfaces results in high contact resistance in this interface than the TRIP combination. For both combinations, the heat generation is higher in interface " $\mathrm{B}$ " than interface " $A$ ", and melting usually occurs in the interface of high heat generation.

It is reported that in three sheets spot welding, if all the sheets are similar combination, the melting will start in geometric center or either any of the interfaces. The location of melting depends on the distance to water cooled electrode and the thickness of sheets ${ }^{4}$. But for dissimilar material welding, the beginning of melting is more complicated. To investigate the initial melting location, resistance spot welding was performed at $7.5 \mathrm{kA}$ and 5 cycles. The melting is observed in interface " $\mathrm{B}$ " 


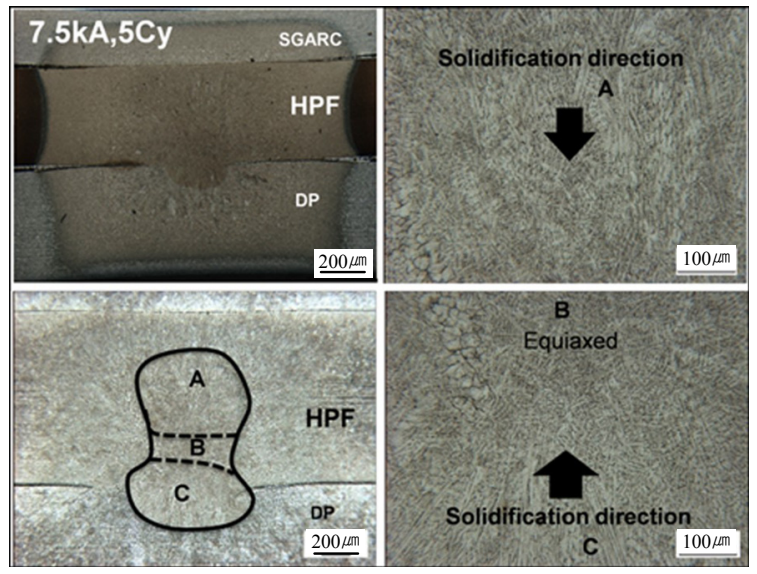

Fig. 4 Coalescence of two nuggets in Al-HPF combination during early resistance spot welding time

for both combination, and nugget is formed between the middle and bottom sheet. The nugget size is more extensive for the TRIP combination than the one of the Al-HPF combination. in this interface. However, a different phenomenon is observed in the case of Al-HPF combination. At higher magnification, Al-HPF combination shows the presence of two nuggets (Fig. 4). The other nugget form close to the geometric center of the middle sheet of the Al-HPF combination. The solidification direction of both nuggets and equiaxed grain in the merging point of two nuggets confirms the presence of two nuggets. It is believed that the heat generated in two interfaces of Al-HPF combination due to high contact resistance conducted to the geometric center of the middle sheet. There is also the additional heat generation due to sheet own bulk resistance. The combined effect might initiate the melting in the geometric centre of the middle sheet of the Al-HPF combination. The concave heat flow pattern from both interfaces to the middle sheet suggests the occurrence of heat conduction from both interfaces to the middle. It is mentioned that melting in middle sheet is highly dependent on the mass of the middle sheet in three sheets spot welding. If the mass of the middle sheet is not sufficient enough, melting will occur here as it cannot absorb all heat conducted from both interfaces ${ }^{6}$.

The welds were made at $7.5 \mathrm{kA}$ and 6 cycles to investigate the nugget growth direction, and its macro- structures are shown in Fig. 5. It can be seen that for Al-HPF combination the nugget growth rate is higher electrode direction (Fig. 5(a)). However, for the TRIP combination, the nugget growth rate is higher in sheet direction (Fig. 5(b)). As for Al-HPF combination nugget growth rate is higher in electrode direction, it should give larger penetration and nugget diameter in thin sheet with welding schedule of $7.5 \mathrm{kA}$ and 21 cycles. However, the weld growth curve suggest TRIP combination having a

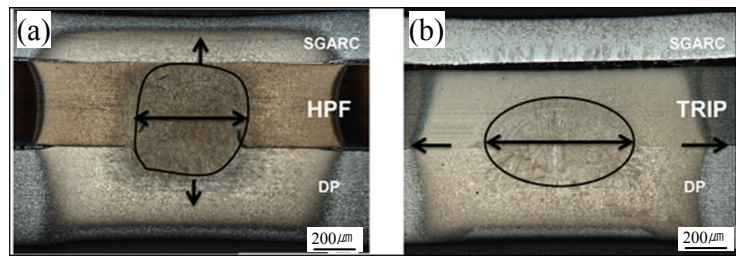

Fig. 5 Comparison of nugget growth at $7.5 \mathrm{kA}$ and 6 cycle welding condition; a) Al-HPF combination b) TRIP combination

higher button diameter than the Al-HPF combination. Therefore, the TRIP combination should have a large nugget diameter in a thin sheet because nugget diameter is proportional to button diameter. So there is a contrast in nugget formation mechanism and nugget diameter.

More detailed observation of the penetration on a thin sheet, the microstructure of thin sheet interface for both combinations are shown in Fig. 6.

The Al- HPF combination nugget having a penetration of $179 \mu \mathrm{m}$ in the thin sheet, which is higher than TRIP combination $(129 \mu \mathrm{m})$ based on optical microstructural confirmation of melting at the interface "A". This could be a reasonable prediction by observing the nugget growth mechanism of two combinations during first 6 welding cycles. The Al-HPF combination shows lower nugget diameter $(3.00 \mathrm{~mm})$ than the TRIP combination in thin sheet, which is different from predicted nugget growth rate pattern.

To investigate this phenomenon, the high speed camera incorporated into the captured images for gaining information on a heat generation pattern during the welding. The video was synchronized and snapshot was captured in cycles. The results are shown in Fig. 7. From the images, it can be seen that for Al-HPF combi-

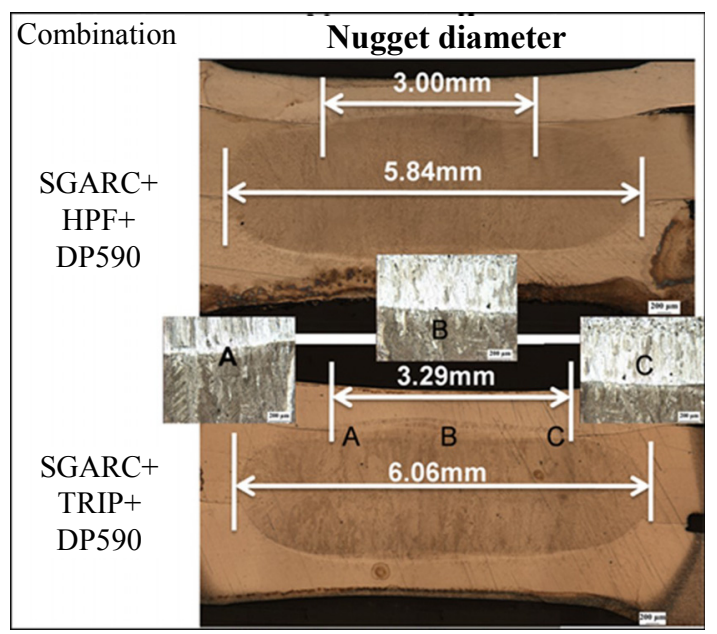

Fig. 6 Penetration depth and nugget diameter comparison in full welding schedule; a) Al-HPF combination b) TRIP combination 


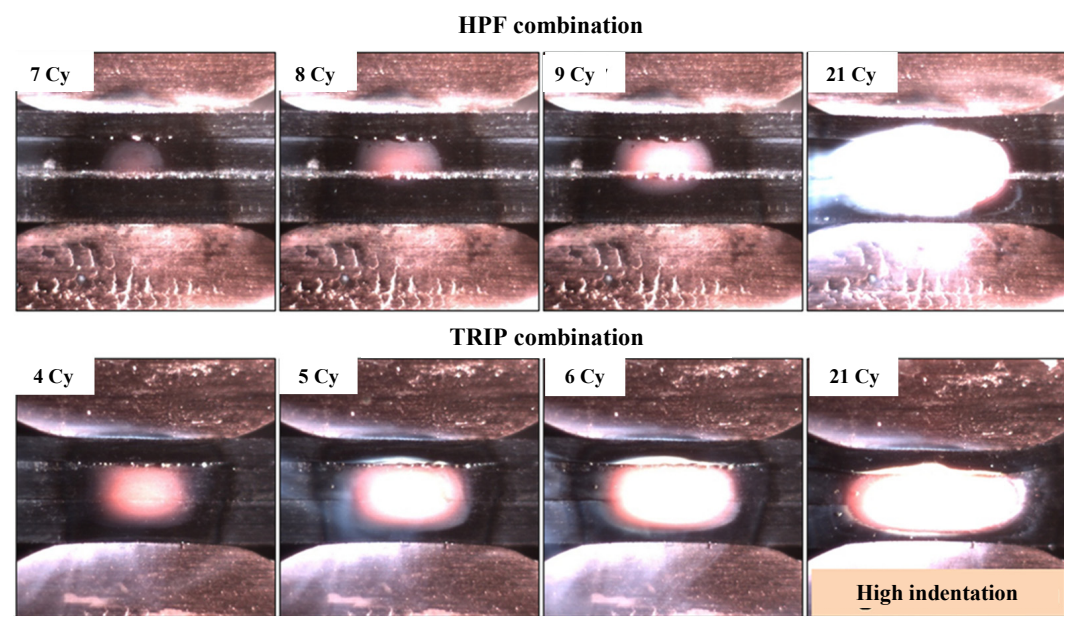

Fig. 7 Comparison of nugget formation mechanism with welding time for HPF combination and TRIP combination (High speed camera still image)

nation melting initiate at 7 cycles (Fig. 7). In the subsequent cycles the Al-HPF shows the nugget growth in electrode direction and finally at 21 cycles shows good penetration in the thinner sheet. This is also observed in the full experimental welding schedule $(7.5 \mathrm{kA}, 21 \mathrm{cy}-$ cle). For TRIP combination the initial melting is much earlier at 4cycles. In the subsequent cycle, it shows nugget growth sheet direction. At end of welding (21 cycle) though there is little penetration in thinner sheet it is having higher nugget diameter in thinner sheet compare to Al-HPF combination. This phenomenon is also observed in full experimental schedule.

Another distinguishable phenomenon is observed in high-speed camera video and snapshots between these two combinations. There is a gradual increase in indentation as the welding goes as nugget grows. The top electrode pushes the top thin sheet into the molten metal, growing from interface " $\mathrm{B}$ " during this gradual indentation. The TRIP combination finally subjected to higher indentation than the Al-HPF combination. To investigate the high indentation phenomena, the hardness of both combination middle sheets is measured since the materials of middle sheet is the only difference between these two combinations. The middle sheet of the Al-HPF combination has almost two times of hardness than the one of the TRIP combination, as shown in Fig. 8. However, it is difficult to conclude the effect of hardness on indentation at high temperature, which is close to the melting temperature of the steel sheet. It is more reasonable that the higher heat generation at early welding time in the TRIP combination than the Al-HPF combination contributes the more substantial amount of plastic deformation for the indentation.

Moreover in SORPAS ${ }^{\circledR}$ simulation, it was found the temperature profile of TRIP combination along inter-

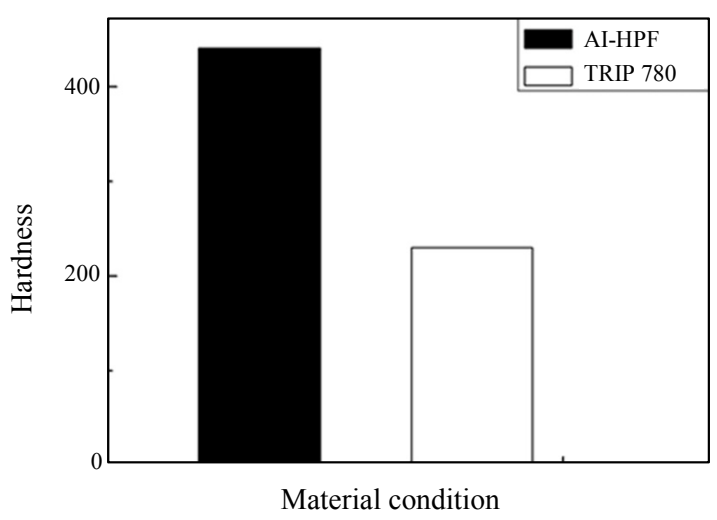

Fig. 8 Hardness comparison of middle sheet of HPF combination and TRIP combination

face " $A$ " and middle sheet center line is higher than the Al-HPF combination at a simulation schedule of 7.5 $\mathrm{kA}$, and 21 cycles (Fig. 9), which suggests heat generation is higher TRIP combination. This high heat generation might be due to the higher chemical composition of TRIP 780. Heat generation in sheets will be followed by a change in the properties of sheets. Consequently, the strength of the steel sheets decreases, and larger indentation can occur, leading to an increase in the contact area between electrode to top sheet and top sheet to the middle sheet. Besides, there is an increase in dynamic resistance due to an increase in bulk resistance as temperature rise ${ }^{7)}$. This high temperature generates more melting in the fusion zone. Thereby nugget volume is a higher for the TRIP combination than AlHPF combination as shown in Fig. 10(a). Both this low hardness as well as high nugget volume in TRIP combination cause a high indentation in the TRIP combination. It is reported that the mechanical properties, as well as nugget volume, has relevance to indentation. The in- 

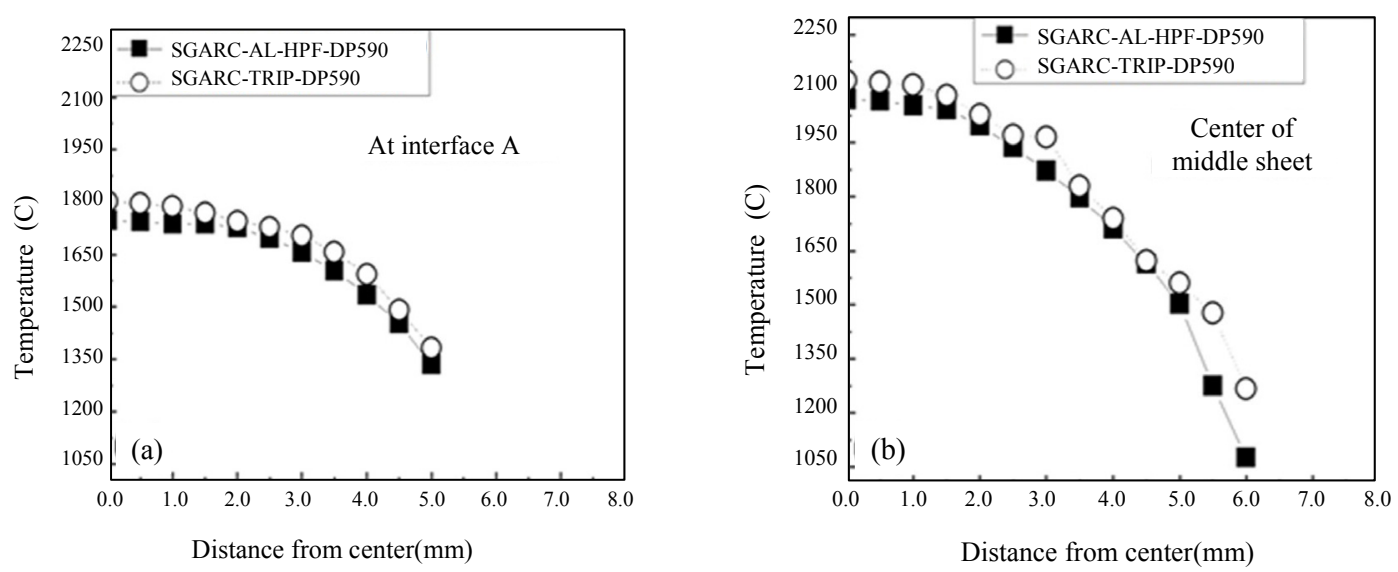

Fig. 9 Temperature profile comparison along interface "A" and centre line of middle sheet at wdling current of 7.5 kA for HPF combination and TRIP combination
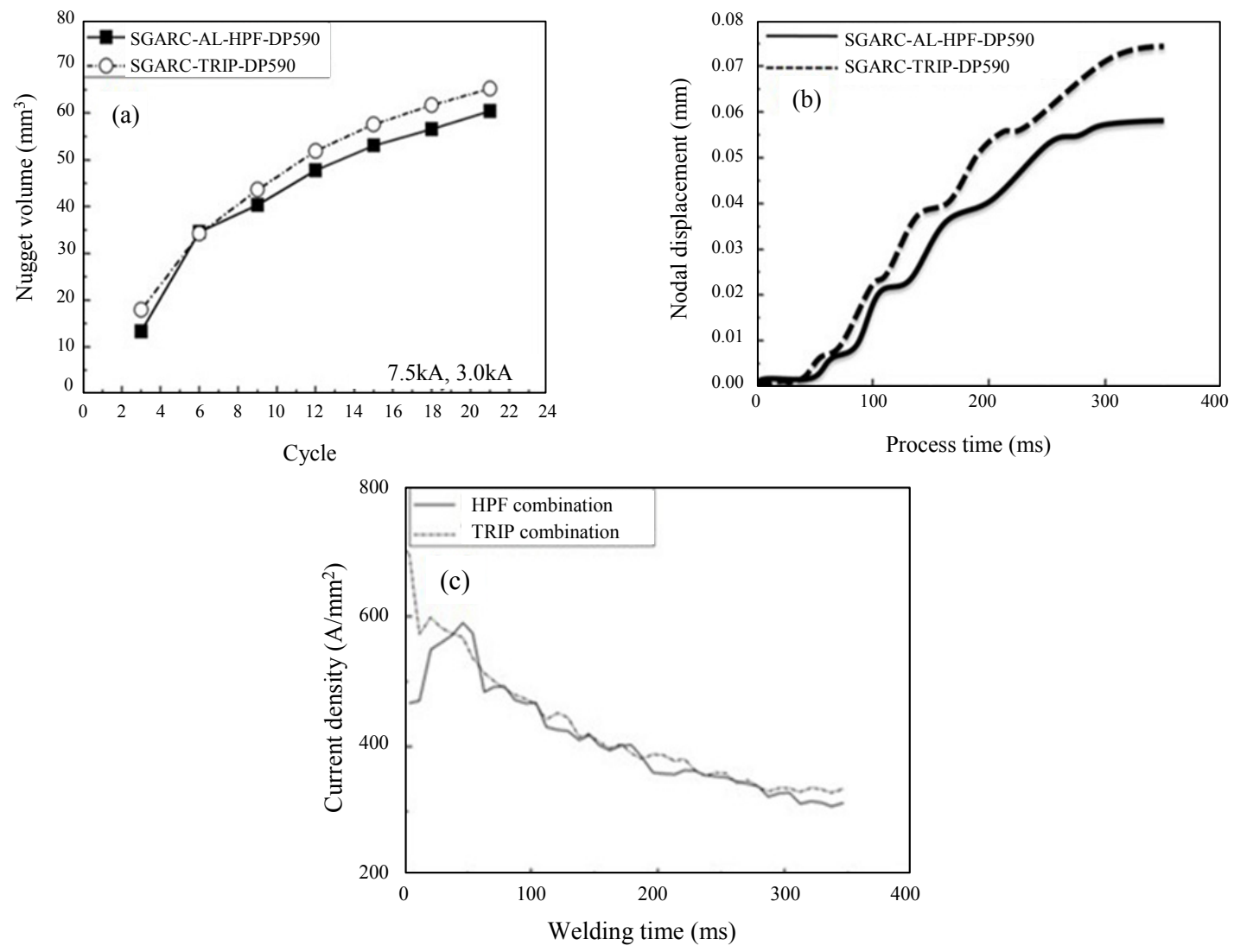

Fig. 10 (a) Nugget volume, (b) electrode displacement, and (c) current density difference at interface "A" for HPF combination and TRIP combination based on SORPAS ${ }^{\circledR}$ simulation schedule of $7.5 \mathrm{kA}$ and $3.5 \mathrm{kN}$

dentation increase with the increase of welding current and indentation has the primary relevance to nugget volume $^{8)}$. The indentation difference also observed in Fig. 10(b), which the data were given from SORPAS ${ }^{\circledR}$ simulation. Here weld time is plotted as millisecond where $16.67 \mathrm{~ms}$ means 1 cycle. The electrode displacement is taken between two nodal points. The two nodal points are taken at top-electrode to top sheet contact point and bottom-electrode to bottom sheet contact point. It is also reported that the electrode to sheet and sheet to sheet deformation influences the weld current density $^{1)}$. In SORPAS ${ }^{\circledR}$ simulation the difference in current density is investigated in interface " $A$ ". The TRIP combination possesses a higher current density than the HPF combination, which is shown in Fig. 10(c).

Moreover, high indentation can influence the contact 

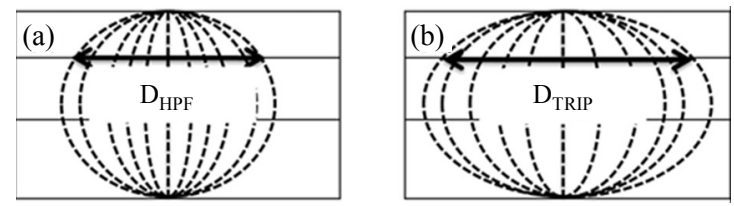

Fig. 11 Difference in current path width of (a) HPF combination and (b) TRIP combination during resistance spot welding

area between electrode to the sheet. It is reported that a soft material will be indented by the electrode more than a hard material. This high indent will cause an increase in the contact area between the sheet and electrode. As TRIP combination middle sheet TRIP 780 having low hardness as well as possesses higher nugget volume during welding, will be subjected to higher indentation than Al-HPF combination as Al-HPF combination middle sheet having high hardness and lower nugget volume during welding. So the current path width will be more extensive for the TRIP combination than the Al-HPF combination which will give higher nugget diameter in a thin sheet of trip combination though penetration can be less in a thin sheet. The mechanism can be shown according to the following Fig. 11. Farson et.al monitored the nugget diameter with change of electrode displacement during the cooling stage of welding ${ }^{9)}$ and found indentation increases the nugget diameter. Nilsen et. al mentioned the observation of gaining higher nugget diameter in a thin sheet in three sheets spot welding due higher indentation ${ }^{2}$. Jo et al. reported larger welding current process window for high electrode force compare to low electrode force in resistance spot welding ${ }^{10)}$. So it can be concluded that though too much indentation is defined as a bad quality in resistance spot welding, it can have significant effect to get good weldability in three sheets spot welding.

\section{Conclusions}

1) Two different combinations (difference in the middle) of three sheets is used to find out the mechanism to get better nugget diameter in a thin sheet in three sheets spot welding. The difference in electro- mechanical properties of the middle sheet provides a significant effect of forming nugget in a thin sheet in three sheets spot welding.

2) Due to higher contact resistance in the interfaces, the HPF combinations show higher heat generation in interfaces than the trip combinations. For TRIP, combination melting was observed in interface " $\mathrm{B}$ ", but for HPF, combination melting was observed in interface
"B" as well as in the geometric center. The reason for melting in the geometric center might be due to the higher heat conduction from both interfaces to the geometric center.

3) The TRIP combinations show nugget growth rate higher in sheet direction while the HPF shows in electrode direction. However at the end of welding, the TRIP combinations show better nugget diameter in thin sheet though it has lower penetration than the HPF combination.

4) The TRIP combination shows better nugget diameter in a thin sheet than HPF combination because of higher indentation resulting from low hardness and high nugget volume. Indentation can increase the nugget diameter by increasing the current density and current path width.

5) The material with proper bulk resistance and hardness in a middle of three sheets spot welding can give better weldability.

\section{Acknowledgement}

This work was supported by Dong-eui University Grant. (201902150001)

ORCID: Nazmul Huda: https://orcid.org/0000-0001-5857-5278 ORCID: Dae-Geun Nam: http://orcid.org/0000-0003-2360-722X ORCID: Yeong-Do Park: http://orcid.org/0000-0002-0165-4749

\section{References}

1. J. Shen, Y. Zhang, X. Lai and P. C. Wang, Modeling of Resistance Spot Welding of Multiple Stacks of Steel Sheets, Mater. Des, 32(2) (2011) 550-560. https://doi.org/10.1016/j.matdes.2010.08.023

2. C. V. Nielsen, K. S. Friis, W. Zhang and N. Bay, ThreeSheet Spot Welding of Advanced High-strength Steels, Weld. J. 90(2S) (2011) 32s-40s.

3. J. Gould, W. Peterson and J. Cruz, An Examination of Electric Servo-guns for the Resistance Spot Welding of Complex Stacks-ups, Weld. World, 57(2) (2013) 243-256. https://doi.org/10.1007/s40194-012-0019-x

4. N. D. Uijl, Resistance Spot Wlding of Cmplicated Joint in New Advanced High Strength Steel, Proceeding 6th Int. Seminar on Advances in Resistance welding. Hamburg, (2010) 40-54.

5. N. Huda and Y. D. Park, Weldability Evaluation and Nugget Formation Mechanism in Three Sheets Spot Welding, Trends Weld. Res. (2012) 680-684.

6. N. Harlin, T. B. Jones and J. D. Parker, Weld Growth Mechanisms During Resistance Spot Welding of Two and Three Thickness Lap Joints, Sci. Technol. Weld. Join. 7(1) (2002) 35-41.

https://doi.org/10.1179/136217102225001494 
7. J. Senkara, H. Zhang and S. J. HU, Expulsion Prediction in Resistance Spot Welding, Weld. J. 83(4) (2004) 123-S.

8. F. Hayat, The Effect of the Welding Current on Heat in Put, Nugget Geometry and the Mechanical an Fractural Properties of Resistance Spot Welding on $\mathrm{Mg} / \mathrm{Al}$ Dissimilar Materials, Mater. Des. 32(4) (2011) 2476-484. https://doi.org/10.1016/j.matdes.2010.11.015
9. D. F. Farson, J. Z. Chen, K. Ely and T. French, Monitoring Resistance Spot Nugget Size by Electrode Displacement, J. Manuf. Sci. Eng. 126(2) (2004) 391-394.

10. H. Jo, Y. Kim, M. Kang and D. Kim, Effects of Electrode Face Radius and Force on Resistance Spot Weldability of Aluminium Alloy 6061, J. Weld. Join. 36(6) (2018) 46-51.

https://doi.org/10.5781/JWJ.2018.36.6.8 